\title{
Determinants of job motivation among frontline employees at hospitals in Tehran
}

\author{
Ehsan Zarei $^{1}$, Marziye Najafi ${ }^{1,2}$, Roya Rajaee ${ }^{3}$, Abbas Shamseddini ${ }^{1}$
}

\author{
${ }^{1}$ Department of Public Health, School of Health, Shahid Beheshti University of Medical Sciences, Tehran, Iran \\ ${ }^{2}$ Imam Khomeini Hospital, Tehran University of Medical Sciences, Tehran, Iran \\ ${ }^{3}$ Alborz University of Medical Sciences, Karaj, Iran
}

\section{Type of article: Original}

\begin{abstract}
Introduction: Human resources are the most strategic resource and the most significant input for health systems. Their behavior and motivation can strongly affect the overall performance of the health systems. The aim of this study was to determine the factors that affect motivation in frontline employees at teaching hospitals affiliated with Shahid Beheshti University of Medical Sciences (SBMU) in Tehran, Iran.

Methods: This cross-sectional study was conducted in 2015. The participants (nurses, physiotherapists, radiology and laboratory technicians, operating room and pharmacy staff) were 300 employees selected by the stratified random sampling method from two general and teaching hospitals. The data collection instrument was a questionnaire that consisted of 42 questions in the 7 domains of motivational factors. Data analysis was performed using descriptive statistics and independent samples t-test by SPSS software, version 23.

Results: The findings indicated that working relationships (mean of 3.95) were the main determinant of job motivation of frontline employees. Job content (3.76) career development (3.75), social respect (3.75), and autonomy (3.30) were the next four affective factors. Recognition and remuneration had the least influence on the job motivation of frontline employees. The results of the Friedman test indicated that the difference between the mean scores of different dimensions was significant $\left(\chi_{(6)}^{2}=607.00, p<0.001\right)$.

Conclusion: A hospital that seeks to engender increased motivation of its frontline employees should have in place a human resources strategy that includes facilitating communication between personnel and management, supporting employees in the community, and promoting social respect for health professions, providing educational opportunities and career development, development of appropriate promotional policies, employee participation in goal setting, facilitating a good working environment and job security, job enrichment, and delegation.
\end{abstract}

Keywords: job motivation, work motivation, frontline employee, teaching hospital

\section{Introduction}

Human resources are the most strategic resource of any organization (1) and are arguably the most significant input for a health system. Their behavior and motivation can strongly affect the overall performance of the health system (2-5). Motivation can be defined as the process responsible for the intensity, orientation, and continuity of individual effort to achieve an objective (3) arising from the interactions between individuals, the workspace, and society (2). Motivation results from a need that must be satisfied, and this, in turn, results in a specific behavior (3). Motivation is a behavioral, affective, and cognitive process that affects employees' trends to perform their tasks to achieve personal and organizational goals (4). Aside from the effect of the shortage of healthcare workers, the lack of motivation in healthcare providers constitutes a major crisis for the health sector. It critically affects the performance, quality, effectiveness, equity, and service delivery of a health system $(2,4,6)$. Ignoring the motivation of providers can hinder the development of health systems (2). The negative results of a lack of motivation include inadequate knowledge translation, underutilization of resources, and weak performance of the health system (2).

\section{Corresponding author:}

Assistant Professor Dr. Ehsan Zarei (Ph.D.), Department of Public Health, School of Public Health, Shahid Beheshti University of Medical Sciences, Tehran, Iran. Tel.: +98.2122432040-41, E-mail: e.zarei@sbmu.ac.ir

Received: October 26, 2015, Accepted: December 22, 2015, Published: April 2016

iThenticate screening: December 22, 2015, English editing: March 26, 2016, Quality control: April 08, 2016

(C) 2016 The Authors. This is an open access article under the terms of the Creative Commons Attribution-NonCommercialNoDerivs License, which permits use and distribution in any medium, provided the original work is properly cited, the use is non-commercial and no modifications or adaptations are made. 
Studies on job motivation have found that a lack of motivation decreases job satisfaction and efficiency, increases absenteeism and turnover, and decreases the quality and the quantity of the work (7). Motivation directly influences the performance of the healthcare providers and their loyalty towards the organization (8). Motivation is important for patient satisfaction and also is required to retain high-performing employees and maintain job satisfaction $(2,9)$. Lack of motivation is a push factor for the migration of providers from rural to urban areas and abroad $(2,4)$. Motivated staff is the key to high-quality and accessible health services and achieving millennium development goals (6). Employee motivation is affected by intrinsic factors (autonomy, competence, social interaction, responsibility, and self-esteem) and extrinsic factors (remuneration, relationship with supervisor and colleagues, recognition) (4). The World Health Organization recommends a combination of intervention in education, regulations, and financial, personal, and professional support to improve the motivation of health workers (10).

Motivation is a primary task of managers; thus, they must have an awareness of employee perspectives on the factors that affect motivation in order to improve it. Awareness of the determining factors that affect the motivation of employees aids implementation of targeted strategies for continuous improvement. Administrators of each organization must achieve organizational objectives by identifying the determining factors in the motivation of their employees. Frontline employees are at the forefront of providing services to patients; they have the closest personal contact with the patients in the hospital. Their service and interaction with patients have an important role in patients' perceptions of the quality of service and in patients' satisfaction and loyalty (11). Although workforce motivation is an important issue in the performance of the health system, few studies have examined its determining factors, especially in developing countries and hospital settings $(2,4)$. This study identified the determining factors of motivation in frontline employees at teaching hospitals affiliated with Shahid Beheshti University of Medical Sciences (SBMU) in Tehran, Iran.

\section{Material and methods}

This cross-sectional study was conducted in 2015 in Tehran, Iran. The study population was comprised of frontline employees (nurses, physiotherapists, radiology and laboratory technicians, staff of operating room and pharmacy) of hospitals affiliated with SBMU. The studied sample consisted of 300 people selected from two general and teaching hospitals. The stratified random sampling method was used. First, the personnel were divided into nurse and nonnurse strata and then random sampling was conducted in each stratum. Three-quarters of the samples were allocated to the nurse group, and the remainder was allocated to non-nurse employees.

The data collection tool was a questionnaire entitled "Determining factors of job motivation from the employee perspective," which had been developed and validated in a previous study (12). This questionnaire contained 42 questions in 7 domains, i.e., working relationships, remuneration, recognition, job content, autonomy, social respect, and career development. The reliability of the questionnaire was measured using Cronbach's alpha coefficient; the coefficients of the domains ranged from 0.68 to 0.86 and indicated acceptable stability of the questionnaire. The items on the questionnaire were ordered as follows: "In your opinion, to what extent do the following factors improve your motivation in your job?" The responses for each item ranged from "very much" (5) to "very little" (1) and the minimum to maximum average score for each motivational domain was 1 to 5 , respectively.

Descriptive statistics (mean and standard deviation) and independent-samples t-test were used to determine the difference between motivational factors among groups using IBM-SPSS software, version 23 . The confidentiality of respondents was preserved during data gathering, and all personnel were free to decide whether to participate in the study. The study was approved by the Research Ethics Committee of the Shahid Beheshti University of Medical Sciences (Ref, No.: 14.2.2015).

\section{Results}

Among the 300 questionnaires that were distributed, 258 were completed and returned (response rate: 86\%). Analysis of the demographic features of the study sample showed that 168 employees $(65 \%)$ were female, 204 (79\%) were over 30 years of age, $140(54 \%)$ had less than 10 years of job experience, $227(86 \%)$ had a university degree, $184(74 \%)$ were nurses, and $74(26 \%)$ worked in other professions. The findings indicated that, among the motivational factors, working relationships (mean of 3.95) had the greatest influence on the job motivation of frontline employees. Career development, social respect, job content, and autonomy were the next four affective factors. Recognition and remuneration had the least influence on motivation of frontline employees (Table 1). The results of the Friedman test indicated that the difference between mean scores among different dimensions was significant $\left(\chi^{2}(6)=607.00, \mathrm{p}<0.001\right)$. 
Table 1. Determinants of motivation among frontline employees

\begin{tabular}{|l|l|l|}
\hline Motivational factors & Mean & SD \\
\hline Working Relationships & 3.95 & 0.87 \\
\hline Job Content & 3.76 & 0.78 \\
\hline Career Development & 3.75 & 0.80 \\
\hline Social Respect & 3.75 & 0.89 \\
\hline Autonomy & 3.30 & 0.65 \\
\hline Recognition & 2.74 & 0.97 \\
\hline Remuneration & 2.60 & 1.00 \\
\hline
\end{tabular}

A comparison of motivational factors based on the demographic variables showed that the effects of suitable working relationships, remuneration, job content, and career development differed according to gender (Table 2). Female employees attached greater importance to remuneration, and males attached greater importance to other factors $(\mathrm{p}<0.001)$. The effect of job content, autonomy, and social respect on motivation was greater in employees under 30 years of age than in employees over 30 years of age $(p<0.05)$. Employees with university degrees allocated greater importance to career development and job content $(\mathrm{p}=0.04)$. Employees with high school diplomas or less education assigned greater importance to working relationships, remuneration, autonomy, and social respect $(\mathrm{p}<0.05)$. A comparison of motivational factors on the basis of job experience (Table 2$)$ showed that employees with less than 10 years of job experience attached more significance to job content, social respect, and career development $(\mathrm{p}<0.05)$. For more experienced employees, remuneration, recognition, and autonomy were more in motivation. A comparison of the motivational factors versus job type (Table 2) showed that nurses attached higher importance to working relationships and job content and that other frontline employees attached greater importance to remuneration, recognition, and social respect $(\mathrm{p}<0.05)$.

Table 2. Comparison of motivational factors among demographic groups

\begin{tabular}{|c|c|c|c|c|c|c|c|c|}
\hline \multirow{2}{*}{\multicolumn{2}{|c|}{ Demographic variables }} & \multirow{2}{*}{\multicolumn{7}{|c|}{ Motivational factors }} \\
\hline & & & \multirow{2}{*}{\begin{tabular}{|l} 
Job Content \\
$4.00 \pm 0.81$
\end{tabular}} & & & & & \\
\hline Age (vear) & $<30$ & \begin{tabular}{|l|}
$\begin{array}{l}\text { Working } \\
\text { Relationships }\end{array}$ \\
$4.24 \pm 0.89$ \\
\end{tabular} & & \begin{tabular}{|l|}
$\begin{array}{l}\text { Career } \\
\text { Development }\end{array}$ \\
$3.93 \pm 0.83$ \\
\end{tabular} & \begin{tabular}{|l|}
$\begin{array}{l}\text { Social } \\
\text { Respect }\end{array}$ \\
$3.83 \pm 0.81$ \\
\end{tabular} & \begin{tabular}{|l|} 
Autonomy \\
$3.42 \pm 0.40$ \\
\end{tabular} & \begin{tabular}{|l|} 
Recognition \\
$2.73 \pm 0.85$ \\
\end{tabular} & \begin{tabular}{|l|} 
Remuneration \\
$2.73 \pm 0.85$ \\
\end{tabular} \\
\hline & $\geq 30$ & $3.87 \pm 0.85$ & $3.68 \pm 0.76$ & $3.71 \pm 0.78$ & $3.72 \pm 0.95$ & $3.26 \pm 0.70$ & $2.74 \pm 0.99$ & $2.75 \pm 0.99$ \\
\hline & $\mathrm{p}$ & 0.16 & 0.04 & 0.27 & 0.01 & $<0.001$ & 0.10 & 0.21 \\
\hline \multirow[t]{3}{*}{ Gender } & Male & $3.97 \pm 0.73$ & $3.81 \pm 0.65$ & $3.81 \pm 0.70$ & $3.92 \pm 0.84$ & $3.23 \pm 0.72$ & $2.64 \pm 0.93$ & $2.42 \pm 0.64$ \\
\hline & Female & $3.94 \pm 0.94$ & $3.72 \pm 0.84$ & $3.73 \pm 0.84$ & $3.66 \pm 0.91$ & $3.33 \pm 0.61$ & $2.79 \pm 0.99$ & $2.70 \pm 0.85$ \\
\hline & $\mathrm{p}$ & $<0.001$ & $<0.001$ & 0.01 & 0.89 & 0.38 & 0.61 & $<0.001$ \\
\hline \multirow[t]{3}{*}{ Education } & Non- university & $4.02 \pm 0.54$ & $3.34 \pm 0.64$ & $3.66 \pm 0.63$ & $4.14 \pm 0.63$ & $3.54 \pm 0.78$ & $3.41 \pm 0.70$ & $3.67 \pm 0.98$ \\
\hline & university & $3.94 \pm 0.91$ & $3.80 \pm 0.78$ & $3.77 \pm 0.82$ & $3.69 \pm 0.91$ & $3.26 \pm 0.62$ & $2.64 \pm 0.92$ & $2.46 \pm 0.89$ \\
\hline & $\mathrm{p}$ & $<0.001$ & 0.04 & 0.04 & 0.01 & 0.01 & 0.15 & $<0.001$ \\
\hline \multirow{3}{*}{\begin{tabular}{|l} 
Job \\
experience \\
(year)
\end{tabular}} & $<10$ & $4.05 \pm 0.93$ & $3.90 \pm 0.87$ & $3.86 \pm 0.93$ & $3.74 \pm 0.80$ & $3.14 \pm 0.44$ & $2.55 \pm 0.70$ & $2.38 \pm 0.93$ \\
\hline & $\geq 10$ & $3.82 \pm 0.83$ & $3.63 \pm 0.71$ & $3.65 \pm 0.70$ & $3.68 \pm 0.97$ & $3.33 \pm 0.71$ & $2.74 \pm 0.50$ & $2.59 \pm 0.83$ \\
\hline & $\mathrm{p}$ & 0.08 & 0.01 & $<0.001$ & 0.04 & $<0.001$ & $<0.001$ & $<0.001$ \\
\hline \multirow[t]{3}{*}{ Job type } & Nurse & $3.97 \pm 0.95$ & $3.84 \pm 0.82$ & $3.75 \pm 0.83$ & $3.67 \pm 0.94$ & $3.21 \pm 0.61$ & $2.52 \pm 0.85$ & $2.37 \pm 0.84$ \\
\hline & Non- nurse & $3.89 \pm 0.65$ & $3.52 \pm 0.62$ & $3.77 \pm 0.70$ & $3.94 \pm 0.72$ & $3.50 \pm 0.71$ & $3.26 \pm 0.98$ & $3.19 \pm 0.98$ \\
\hline & $\mathrm{p}$ & $<0.001$ & $<0.001$ & 0.08 & 0.01 & 0.10 & 0.05 & $<0.001$ \\
\hline
\end{tabular}

\section{Discussion}

This study determined the factors that affect job motivation of frontline employees in teaching hospitals in Tehran, Iran. Four motivational factors (working relationships, career development, social respect, and job content) had the strongest effect on job motivation of the respondents. Intrinsic factors had a greater effect on motivation than extrinsic factors, which was consistent with the results of previous studies in Iran (13, 14), Estonia (9), and Pakistan (2). Vali et al. (15) found that pre-hospital emergency technicians believed psychological factors, such as perceived job responsibility, meaningful work, and job success, were the most important factors that affect motivation. The Herzberg theory (16) states that intrinsic factors have the greatest potential for motivating employees. The employee's relationship with her or his supervisor and colleagues and management support proved to be the most important motivational factors in the present study, which was consistent with the results of previous studies. The leadership style of managers and good working relationship with the supervisor and colleagues played a significant 
role in the motivation of health workers $(4,17,18)$. The lack of managerial skills was cited as a factor that decreased motivation (16). Results of other studies have shown that management support, relationship with the supervisor, and working relationships were the most important motivational factors for nurses (13, 14), hospital managers (19), and healthcare workers (20). Suitable working relationships with colleagues and the supervisor are necessary for hospital personnel who work in teams.

Career development was the second most effective factor for motivation. A systematic review revealed that $85 \%$ of studies on healthcare worker motivation cited career development and educational opportunities as important factors for job motivation (17). A study in Pakistan showed that lack of opportunities for higher qualifications and professional growth were the most important factors that decreased the motivation of physicians (2). Previous studies of Iranian nurses (21), hospital workers in Ghana (22), and primary care providers in China $(8,23)$ indicated the importance of job advancement and the existence of educational opportunities on motivation. When the employees believe they have opportunities for advancement in their profession, they remain motivated. Hamoudzade et al. (19) found that social respect was an important factor that motivates hospital managers. Daneshkohan et al. (20) found that social respect was influential on the job motivation of health workers. Malek et al. (2) recognized social reward as a socio-cultural motivator of Pakistani physicians. These findings indicate that respect for healthcare professions plays an important role in the motivation of employees.

Job content was the fourth most effective factor for motivation. Meaningful work was reported as an important motivational factor among Greek nurses (5) and Cypriot nurses and physicians (3). A study in Iran showed that achieving hospital goals, existence of challenging goals, and participation in determination of goals were important factors that motivated hospital managers (19). The presence of a goal and a specific result for work are important factors for motivation. In the healthcare sector in particular, witnessing the results and effects of efforts by an employee on a patient can provide strong positive motivation.

Recognition and remuneration had less effect on motivation than other factors, which was consistent with the results of previous studies in Iran (20). Tsounis showed that financial incentives did not increase physicians' motivation in the public sector of Greece (24). Findings of studies in Estonia (9) and Greece (5) also were indicative of the low effect of financial factors and salary on motivation in nurses. A systematic review revealed that recognition was less important as a motivational factor than other factors for the primary healthcare providers (17). This finding was consistent with the Herzberg theory that remuneration is a hygiene factor and lacked high motivational potential (16). Financial incentives had an effect on employee motivation, but money was rarely the most important motivational factor $(2,5)$. It appears that developing and using the incentives aimed at fulfilling goals, job enrichment, and recognition in the workplace are more fruitful.

The effect of job content, autonomy, and social respect on motivation was greater for younger employees. The findings of previous studies indicated that age has a significant relationship with motivation and motivational factors (21). One study showed that responsibility had a greater effect on the motivation of young workers (23). In our study, it was determined that female employees attached more importance to the role of remuneration in motivation. Similar results have been reported in studies showing that female physicians and nurses regard financial factors as more important than other factors $(2,3)$.

Nurses attached greater importance to suitable working relationships and job content for motivation. A study in Cyprus indicated that nurses attached less importance to financial factors than physicians (3). It appears that, for nurses, job content and good working relationships with the treatment team had a stronger effect on motivation. Accordingly, hospital management should take appropriate measures to establish good working relationships among the treatment team members to increase the motivation of nurses. The less-experienced employees assigned higher effects for job content, social respect, and career development on motivation. More experienced employees believed that remuneration, recognition, and autonomy had greater effects on motivation. The findings of a study in Estonia showed that experienced nurses were more motivated by extrinsic aspects of their jobs (9). This seems rational; lessexperienced employees require professional advancement and promotions; thus, opportunities for advancement are considered appropriate motivational factors for them. This finding indicates that managers must develop wellthought-out plans for promoting the motivation of their more-experienced employees. Career development and job content had more significant roles in the motivation of employees with higher education. Employees with less education attached more importance to suitable working relationships, remuneration, autonomy, and social respect. Staff with less education receive lower salaries and often have less autonomy because of the nature of their work. 
Employees with higher education have higher expectations from their job and their abilities. For them, jobs that have defined objectives, challenges, and opportunities for growth are more important than other factors, such as remuneration and working relationships.

\section{Study limitations}

Our study had some limitations. First, apart from the factors examined in this study, there are other factors for job motivation that should be studied in future research to get a clearer picture of employees' perspective on job motivation. Second, our findings were obtained from a quantitative study, however, in order to get better results, it should be improved using qualitative studies. Therefore, using qualitative methods in addition to quantitative methods in future studies could provide a better understanding of the factors that enhance job motivation.

\section{Conclusions}

The results of this study showed that the intrinsic aspects of a job were stronger motivators on motivation than the extrinsic aspects, such as salary and financial incentives. Facilitating communication between personnel and management, supporting employees in the community, and promoting social respect for health professions, providing educational opportunities and career development, development of appropriate promotional policies, employee participation in goal setting, facilitating a good working environment and job security, job enrichment, and delegation must be part of the human resource strategy of a hospital that seeks to engender increased motivation of its frontline employees.

\section{Acknowledgments:}

This study was supported financially by Shahid Beheshti University of Medical Sciences under contract number $0307 / 5730$. We sincerely appreciate the cooperation of the hospital personnel who participated in the study.

\section{Conflict of Interest:}

There is no conflict of interest to be declared.

Authors' contributions:

All authors contributed to this project and article equally. All authors read and approved the final manuscript.

\section{References:}

1) Nishtar S, Ralston J. Can human resources for health in the context of noncommunicable disease control be a lever for health system changes? Bull World Health Organ. 2013; 91: 895-6. doi: 10.2471/blt.13.118711. PMID: 24347721, PMCID: PMC3853949.

2) Malik AA, Yamamoto SS, Souares A, Malik Z, Sauerborn R. Motivational determinants among physicians in Lahore, Pakistan. BMC Health Serv Res. 2010; 10(201). doi: 10.1186/1472-6963-10-201, PMID: 20618962, PMCID: PMC2910698.

3) Lambrou P, Kontodimopoulos N, Niakas D. Motivation and job satisfaction among medical and nursing staff in a Cyprus public general hospital. Hum Resour Health. 2010; 8(26). doi: 10.1186/1478-4491-8-26. PMID: 21080954, PMCID: PMC2998451.

4) Okello DR, Gilson L. Exploring the influence of trust relationships on motivation in the health sector: a systematic review. Hum Resour Health. 2015; 13(16). doi: 10.1186/s12960-015-0007-5, PMID: 25889952, PMCID: PMC4384237.

5) Gaki E, Kontodimopoulos N, Niakas D. Investigating demographic, work - related and job satisfaction variables as predictors of motivation in Greek nurses. J Nurs Manag. 2013; 21: 483-90. doi: 10.1111/j.1365-2834.2012.01413.x, PMID: 23409751.

6) Mutale W, Ayles H, Bond V, Mwanamwenge MT, Balabanova D. Measuring health workers' motivation in rural health facilities: baseline results from three study districts in Zambia. Hum Resour Health. 2013; 11(8). doi: 10.1186/1478-4491-11-8, PMID: 23433226, PMCID: PMC3608223.

7) Bahadori M, Babaei M, Mehrabian F. Prioritization of Factors Influencing Job Motivation in Employees of a Military Center Using Analytical Hierarchy Process (AHP). J Mil Med. 2013; 14: 237-44

8) Hung L-M, Shi L, Wang H, Nie X, Meng Q. Chinese primary care providers and motivating factors on performance. Fam Pract. 2013; 30: 576-86. doi: 10.1093/fampra/cmt026, PMID: 23788201.

9) Toode K, Routasalo P, Helminen M, Suominen T. Hospital nurses' work motivation. Scand J Caring Sci. 2015; 29(2): 248-57. doi: 10.1111/scs.12155, PMID: 24909713. 
10) Bonenberger M, Aikins M, Akweongo P, Wyss K. The effects of health worker motivation and job satisfaction on turnover intention in Ghana: a cross-sectional study. Hum Resour Health. 2014; 12(43). doi: 10.1186/1478-4491-12-43, PMID: 25106497, PMCID: PMC4130118.

11) Zarei E, Arab M, Tabatabaei SM, Rashidian A, forushani AR, Khabiri R. Understanding patients' behavioral intentions: Evidence from Iran's private hospitals industry. J Health Organ Manag. 2014; 28(6): 795-810. doi: 10.1108/jhom-11-2012-0218, PMID: 25507341.

12) Taeebi Z. Motivating factors among hospital managers in teaching hospitals of Iran University of Medical Sciences, Tehran. Tehran: Iran University of Medical Sciences; 1999.

13) Mahmoudi H, Ebrahimian A, Solymani M, Ebadi A, Hafezi S, Fayzi F, et al. The study of job motivation factors in critical care nurses. Journal of Behavioral Sciences. 2007; 1: 171-8.

14) Jodat S, Farajzadeh Z, Saadatjoo SA. A study of job motivation of nurses working in Valiasr Hospital of Birjand in 2013. Modern Care J. 2014; 10: 296-304.

15) Vali L, Ghorbani Nia R, Shirkhani H, Zol Ala F. Comparison of the job motivation of staff worker with management emergency medical center's operational staff, kerman university of medical Sciences -2013. Iranian Journal of Nursing Research. 2015; 10: 61-70.

16) Robbins S, Judge TA, Millett B, Boyle M. Organisational behaviour. New York: Pearson Higher Education AU; 2013.

17) Willis-Shattuck M, Bidwell P, Thomas S, Wyness L, Blaauw D, Ditlopo P. Motivation and retention of health workers in developing countries: a systematic review. BMC Health Serv Res. 2008; 8(247). doi: 10.1186/1472-6963-8-247. PMID: 19055827, PMCID: PMC2612662.

18) Toode K, Routasalo P, Suominen T. Work motivation of nurses: a literature review. Int J Nurs Stud. 2011; 48: 246-57. doi: 10.1016/j.ijnurstu.2010.09.013, PMID: 20947085.

19) Hamouzadeh P, Sadeghifar J, Moradkhani B. Factors affecting on job motivation from the managers point of view in teaching hospitals affiliated to Urmia uinversity of medical sciences. Journal of Nursing and Midwifery Urmia University of Medical Sciences. 2011; 9: 15-22.

20) Daneshkohan A, Zarei E, Mansouri T, Maajani K, Ghasemi MS, Rezaeian M. Factors Affecting Job Motivation among Health Workers: A Study From Iran. Glob J Health Sci. 2014; 7(3): 153-60. doi: 10.5539/gjhs.v7n3p153, PMID: 25948438.

21) Negarandeh R, Dehghan-Nayeri N, Ghasemi E. Motivating factors among Iranian nurses. Iran J Nurs Midwifery Res. 2015; 20: 436-41. doi: 10.4103/1735-9066.161011, PMID: 26257797, PMCID: PMC4525340.

22) Adzei FA, Atinga RA. Motivation and retention of health workers in Ghana's district hospitals: addressing the critical issues. J Health Organ Manag. 2012; 26: 467-85. doi: 10.1108/14777261211251535, PMID: 23115900 .

23) Li L, Hu H, Zhou H, He C, Fan L, Liu X, et al. Work stress, work motivation and their effects on job satisfaction in community health workers: a cross-sectional survey in China. BMJ open. 2014; 4: e004897. doi: 10.1136/bmjopen-2014-004897, PMID: 24902730, PMCID: PMC4054641.

24) Tsounis A, Sarafis P, Bamidis P. Motivation among Physicians in Greek Public Health-Care Sector. Br J Med Med Res. 2014; 4: 1094-105. doi: 10.9734/bjmmr/2014/6821. 